\title{
Temporal and spatial variability of settlement success and recruitment level in three blennoid fishes in the northwestern Mediterranean
}

\author{
E. Macpherson*, U. Zika \\ Centro de Estudios Avanzados de Blanes (CSIC), Cami de Santa Barbara s/n, E-17300 Blanes, Girona, Spain
}

\begin{abstract}
We studied the settlement success and recruitment level of 3 common species of blennoids (Aidablennius sphynx, Parablennius incognitus and Tripterygion tripteronotus) off the NW Mediterranean coast at 3 localities separated ca $50 \mathrm{~km}$ apart, over a period of 4 yr (1994 to 1997). Settlement success is defined as the maximum number of new individuals observed during the settlement period and recruitment level as the number of new individuals at the end of the settlement period. We also determined which descriptive variables of the substratum had a significant influence on settlement, and whether the presence of adults had an effect on settlement. The results from the stepwise multiple regression analysis indicated that the type of substrate cover and the presence of adult conspecifics played a significant part in the abundance of settlers and post-settlers on the rocky shore for all 3 species. The variation in the abundance of settlers of $A$. sphynx was best explained by the category 'bare rock' Settlement variance of $P$. incognitus and $T$. tripteronotus was mainly explained by the substrate covered with 'small turf of algae' Field experiments demonstrated a strong relationship between 'bare rock' density and $A$. sphynx settlement and between 'small turf of algae' density and $P$. incognitus and $T$ tripteronotus settlement. However, the strong correlation between settlers and adult conspecifics in the stepwise multiple regression seems to be causal. For the 3 blennoids, preferences for a specific substratum type at settlement can explain, on small scale, the abundance of new settlers in a locality. The maximum density of settlers was only dependent on the amount of preferred substrate available along a transect and independent of the size of a transect. The spatial and temporal patterns of the recruitment level differed from those observed in settlement success. For $A$. sphynx, no significant temporal and spatial differences were found for settlement success but were for recruitment level. For $P$. incognitus, no significant differences were found for settlement success, but a significant spatial variation was observed for recruitment level. For $T$. tripteronotus, the most significant differences were found for settlement success between years, which appeared in patterns of recruitment level. This suggests that the interannual differences were very strong and were maintained throughout the post-settlement period. For this species, significant differences of settlement success were also found between localities, however, they were not maintained over the season. Our results demonstrate that post-settlement processes can alter settlement patterns.
\end{abstract}

KEY WORDS: Settlement · Recruitment - Population dynamics · Habitat selection · Fish · Mediterranean

\section{INTRODUCTION}

The input of new individuals to a population is one of the most important processes in the life history of fishes and, to a large extent, affects their population dynamics (Cushing 1996). The addition of new individ-

•E-mail: macpherson@ceab.csic.es uals in most fish populations is determined by events occurring at settlement, defined as the period when pelagic larvae reach the bottom, and between this period and recruitment, defined as the time at which the juveniles remaining at the end of the settlement period incorporated into the adult populations (see the review of Caley et al. 1996).

The number of larvae that reach the bottom is affected by a variety of abiotic (e.g. currents, wind, waves; 
Cowen 1985, Kingsford et al. 1991, Sabates \& Maso 1992, Leis 1994, Breitburg et al. 1995, Sabates \& Olivar 1996), and biotic (e.g. predation, starvation; MacKenzie \& Leggett 1991, Bailey et al. 1995) processes and could be responsible for the year-class strength (Milicich et al. 1992). However, recent studies have demonstrated the importance of the processes occurring during the post-settlement period (e.g. habitat limitation, predation, competition) in recruitment strength and consequently in the final incorporation of new individuals to populations (e.g. Bailey 1994, Booth \& Beretta 1994, Carr 1994, Beets 1997. Connell 1997, Hixon \& Carr 1997, Macpherson et al. 1997). For these reasons, the identification of these processes and how they affect settlement success and recruitment level is one of the main goals in the study of fish populations (Doherty \& Fowler 1994, Caley et al. 1996).

In recent years, studies on fish settlement and recruitment processes have become more abundant on coral and temperate rocky reefs (see the reviews of Jones 1991, Caley et al. 1996). Some of these studies have demonstrated the positive/negative or neutral influence of habitat factors, among them the selection of substratum characteristics (Shulman et al. 1983, Jones 1991, Levin 1994, García-Rubies \& Macpherson 1995). The presence or absence of conspecifics has also proven to be of great importance in determining the level of settlement and recruitment success for fish (Jones 1987, Sweatman \& St John 1990). The influence of these variables has also been demonstrated in the settlement and post-settlement processes of marine invertebrates (Raimondi 1990, Lopez et al. 1998, Uriz et al. 1998), emphasising the importance of these factors in the study of benthic population dynamics.

The adequate study of the relationship between habitat variables and settlement success and recruitment level can permit the analysis of their spatial and temporal variability, facilitating our understanding of the role of these events in the dynamics of fish communities (Caley et al. 1996). Most studies on settlement and recruitment processes of fishes have been conducted on small spatial and temporal scales (see Doherty 1991, Jones 1991 and references therein); however, studies conducted on scales of kilometres along the coast and over a number of years are rare (Fowler et al. 1992, Tolimieri 1995, 1998, Caselle \& Warner 1996, Levin et al. 1997, Vigliola et al. 1998). As several authors have pointed out (e.g. Dayton \& Tegner 1984, Levin 1988), the scale of a study may influence the patterns that emerge. Therefore, research on these processes should include their spatial and temporal variation at different scales. This procedure would allow to determine whether patterns observed at small scales are also exhibited at larger scales (Levin et al. 1997).
In the present paper, we have studied the settlement success and recruitment level of 3 common benthic littoral species of blennoids (Aidablennius sphynx, Parablennius incognitus and Tripterygion tripteronotus) from the NW Mediterranean Sea (Macpherson 1994). Three localities were studied separated ca $50 \mathrm{~km}$ from each other over a period of $4 \mathrm{yr}$. We selected these species because they are taxonomically close, they live in the same littoral zone and habitats, and they settle to the bottom and recruit to the adult population at nearly the same time. These similarities can provide interesting information about the generality of the patterns observed.

The objectives of the present study were the following: (1) to determine which habitat characteristics have a significant influence in settlement, considering the descriptive variables of the substratum and the presence of adult conspecifics, and (2) once the habitat variables that affect settlement had been delimited, to analyse the importance of spatial and temporal variations of settlement success and recruitment level. We considered the settlement success to be the maximum number of new individuals observed during the settlement period and recruitment level to be the number of new individuals at the end of the settlement period that will incorporate into adult populations.

\section{STUDY SPECIES AND AREA}

Blennids and 3-fin blennids (Families Blenniidae and Tripterygiidae, respectively) form one of the most common groups of the Mediterranean rocky shore fishes (Corbera et al. 1996). On the coast of the NW Mediterranean Sea one finds about 18 species, along the shallow zones of the littoral mainly in the upper 0 to $1 \mathrm{~m}$ below the surface (Zander 1986). The 3 most abundant species are Aidablennius sphynx, Parablennius incognitus, and Tripterygion tripteronotus with a maximum of 7 individuals of each species $\mathrm{m}^{-2}$ (Illich \& Kotrschal 1990, Macpherson 1994). It is these 3 species which will be discussed in the present study.

Some life history characteristics of these fishes are known (e.g. Koppel 1988, Abel 1993). The breeding season is from February until July. Mating males usually build nests during this season and attend the deposited eggs (e.g. Wirtz 1978, Almada \& Santos 1995, Kraak 1996), which are laid on the rocky shoreline. Once hatched, larvae disperse offshore. Little information is available on this process and on the pelagic phase of the life cycle. For some Mediterranean blennoid species, larval development is known and described (Sabates 1994). The larvae of the 3 studied species are differently distributed in the plankton: the larvae of Tripterygion tripteronotus hardly with- 
draw from the coast (ca 100 to $300 \mathrm{~m}$ ), whereas the larvae of Aidablennius sphynx and Parablennius incognitus can be found various miles off shore (Sabates 1994 and pers. comm.). Blennids and 3-fin blennids, in general, have a short life span from 2 to 5 yr (Gordina et al. 1972, Kotrschal \& Goldschmid 1981 and unpubl. dataj. Adults and juveniles of these common species are preyed upon by other fish species (e.g. Serranus cabrilla, Oblada melanura, authors' pers. obs.).

Very little is known about settlement processes and the settler's habitat needs. The rocky substrate of the shallow zone along the Spanish coast of the NW Mediterranean is covered by the same dominant communities, mostly algae, barnacles Chthamalus stellatus and the bivalve Mytilus galloprovincialis (Ros et al. 1985). The most dominant species of the algal community are Corallina elongata, C. granifera, Cladophora spp., Rissoella verruculosa, Lithophyllum tortuosum, Ralfsia verrucosa, and Enteromorpha spp. and usually their abundances are maintained stable over the season when settlement takes place (Ros et al. 1985, Ballesteros 1987). Only a few species (e.g. Cystoseira mediterranea, Enteromorpha spp.) show alterations in their abundance between different months with higher abundances in May and June.

\section{MATERIAL AND METHODS}

The present study was divided into 3 parts based on the 2 objectives above. First, we investigated the habitat characteristics that best explain the abundance of new settlers by a correlative approach. Second, to test the effects of the significant habitat characteristics (algal cover and presence of conspecific adults, see 'Results'), we experimentally manipulated both variables to detect possible causal relationships with abundances of settlers. In the last part, settlement and recruitment were analysed for differences between localities and years.

Habitat selection. Three localities along the rocky shore of the Costa Brava, in the NW Mediterranean Sea, were sampled. The localities were Port de la Selva, the Medes Islands, and Blanes, (Fig. 1), and are roughly $50 \mathrm{~km}$ apart. Data collection has been carried out along rocky walls, following transects between the surface and $1.5 \mathrm{~m}$ depth, during the 4 settlement seasons from 1994 to 1997.

Data on settlement and habitat were collected by sampling 14 transects in July and August of every year. Five transects were sampled by snorkelling in Port de la Selva (totalling to $109 \mathrm{~m}^{2)}, 6$ transects in the Medes Islands $\left(52 \mathrm{~m}^{2}\right)$, and 3 transects in Blanes $\left(69 \mathrm{~m}^{2}\right)$. The area of each transect varied between 6 and $46 \mathrm{~m}^{2}$ because the number and length of the transects were

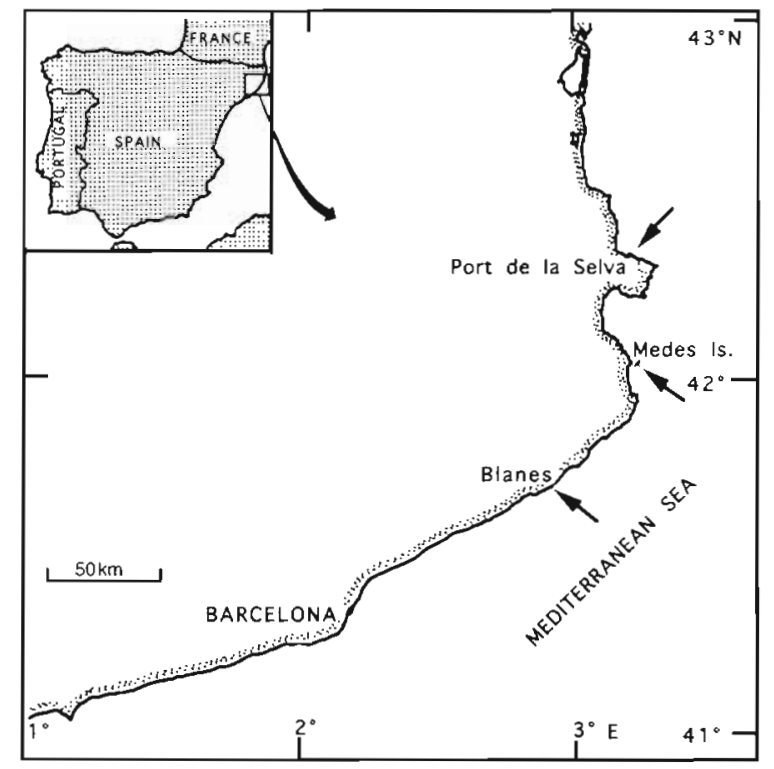

Fig. 1 Location of the study sites (Port de la Selva, Medes Islands and Blanes) along the northwestern Mediterranean coast. Arrows indicate study sites

limited by topographic characteristics of the locale and ease of access during the whole settlement season. Each wall was horizontally separated by discontinuities such as sandy beaches or deep intrusions, and vertically in depth by sandy bottoms or pebbles. While algal and barnacle communities were similar at the 3 localities, the bivalve Mytilus galloprovincialis was not present in Blanes.

Three dives transect ${ }^{-1} \mathrm{Yr}^{-1}$ were carried out at each locality during the settlement season. Along each transect, the observer swam very slowly, from one end of the transect to the other, and a $1 \mathrm{~m}^{2}$ square frame was gently placed on the bottom in order not to disturb and scatter the fishes. In each frame divers recorded (A) the percentage of each substratum type: (1) bare rock; (2) small turf algae, 0.5 to $1 \mathrm{~cm}$; (3) long turf algae, 1 to $2 \mathrm{~cm}$; (4) long turf algae $>2 \mathrm{~cm}$; (5) Mytilus galloprovincialis; (B) rugosity, 4 defined classes, using the chain method (Luckhurst \& Luckhurst 1978); and (C) slope, classified as gentle (0 to $15 \%$ ), pronounced (16 to $30 \%$ ), steep ( 31 to $60 \%$ ), and very steep (>60\%). The substrate type 'bare rock' included zones with the encrusting algae Ralfsia verrucosa and the occasional presence of short algae $(<0.5 \mathrm{~cm}$ in height, e.g. Enteromorpha clathrata). Individuals of all species (blenniid and 3-fin blenniid) present in each $1 \mathrm{~m}^{2}$ quadrant were counted and their sizes recorded, but only the 3 most abundant species, Aidablennius sphynx, Parablennius incognitus, and Tripterygion tripteronotus, have been analysed. Size was estimated by plastic trays bearing the silhouettes of individuals of different size-classes 
(0.5 cm increments) to minimize errors (e.g. GarcíaRubies \& Macpherson 1995, Harmelin-Vivien et al. 1995). New settlers of the 3 species, with total length of about 1.0 to $1.5 \mathrm{~cm}$, were easily distinguishable from each other: A. sphinx is practically unpigmented when settling, whereas $P$. incognitus was slightly pigmented similar to the adult color pattern. $T$ tripteronotus was recognisable by its body shape and a color pattern similar to adults.

A stepwise multiple regression analysis was made on each of the 3 localities to determine which habitat variable best explained the abundance of the new settlers. In total, 9 independent variables were taken into consideration: the percentages of the 5 cover categories, rugosity, slope and the 2 fish variables (number of adult conspecifics and non-conspecifics). Normal probability plots were produced to check whether the assumption of normality is violated and means were plotted against standard deviations to check for outliers.

Effect of substratum type and densities on settlement. All of the following experiments were done on rocky walls in Blanes, Spain, in the upper littoral zone during the 1995 settlement season. Predominant winds and waves are from the north-east to the east and walls had nearly the same orientation, so that atmospheric and oceanographic conditions were the same along their whole length. Nearly homogenous walls, of little rugosity and without intrusions or extrusions, were selected. The experiments could only be conducted during the peak settlement period (for Aidablennius sphynx in July and for Parablennius incognitus and Tripterygion tripteronotus in August) to get a sufficient number of individuals.

Based on our preliminary results of 1994, 'bare rock' was found to explain best the variation in settlement of Aidablennius sphynx, consequently, we manipulated the density of this substratum type to test its effect on settlement of this species. The same procedure was carried out in Parablennius incognitus and Tripterygion tripteronotus, using 'small turf algae 10.5 to $1 \mathrm{~cm}$ height)'. To analyse the effect of substratum type, $1 \mathrm{~m}^{2}$ quadrants were manipulated by scraping algae from. surfaces, leaving selected densities bare rock for A. sphynx and small turf algae for $P$. incognitus and T. tripteronotus) of different percentages: 20 (low); 50 (medium); and $80 \%$ (high); with 4 replicates for each density. A $1 \times 1 \mathrm{~m}$. PVC frame, subdivided in 16 smaller squares, was used to quantify the percentage of substratum type. The distance between the quandrants was at least $5 \mathrm{~m}$. Each quadrant was isolated from the adjacent areas by additionally scraping a $1.5 \mathrm{~m}$ wide section around the perimeter and then applying bleach so no living organism would remain. No artificial effect. of bleach application was noted and no settlers were observed in the cleaned strips during the experiment.
This procedure was used instead of artificial small rocks because it is believed to reflect a more natural condition that an individual finds when settling. All the adults and juveniles of blennoid species were removed from the quadrants to eliminate their possible effect on settlement. After $24 \mathrm{~h}$, the number of new settlers per $\mathrm{m}^{2}$ was counted for each of the 3 densities and all 4 replicates. This procedure was repeated 3 times during the month of peak settlement for each species. No adults (conspecifics or non-conspecifics) were observed in the quadrants or in the cleaned zone around the quadrants during the experiments.

The effects of algal densities and day of experiment on the abundance of settlers were determined in a 2-factor ANOVA and differences among means were assessed using the Tukey HSD test.

Effect of presence/absence of conspecifics on settlement. To analyse the influence of the presence of conspecific adults on the abundance of new settlers, quadrants similar to those used above were used, but with constant substrate conditions in the presence or absence of adults. To test the effect on Aidablennius sphynx, quadrants of bare rock were used. For Parablennius incognitus and Tripterygion tripteronotus, a cover density of more than $80 \%$ of small turf algae ( 0.5 to $1 \mathrm{~cm}$ in height) was used. The density of each of these species is known to be from 1 to 5 ind. $\mathrm{m}^{-2}$ along this coast (Macpherson 1994). Given this, an adult density of 2 to 3 ind. $\mathrm{m}^{-2}$ was tested for its influence on settlement. For each of the species, 4 quadrants without and 4 with conspecifics were examined. To exclude possible migrations of settlers, quadrants with and without adults were situated on 2 different walls, separated horizontally on both sides by either deep and wide intrusions or sandy beaches, and vertically on the bottom by sandy substrate or pebbles. The distance between the quadrants was 3 to $5 \mathrm{~m}$. To avoid adult migrations from the nearby areas into the quadrants, all individuals on both walls were collected, leaving only the desired 2 to 3 adults per quadrant. Two days prior to the experiment, the number of adults per quadrant was observed and if the adult densities differed from 2 to 3 ind. $\mathrm{m}^{-2}$, their numbers were adjusted by replacing or removing individuals. In the majority of the cases the adults were males sitting in their nests which facilitated their remaining in the quadrant. Once verified that adult density remained stable in the quadrants, all juveniles were captured. and 24 h later the number of new settlers in each quadrant was counted. This experiment was repeated on 5 different days.

The effects of presence/absence of adult conspecifics and day of settlement were determined in a 2-factor ANOVA and differences among means were compared using the Tukey HSD test. 
Study of variations in settlement success and recruitment level between localities and years. To analyse a possible variation in settlement success and recruitment level between localities and years, and to quantify both events, the 14 transects were sampled weekly from June to first half of October, when weather conditions permitted. During each dive settlers of all 3 species were counted and their sizes noted as above. The maximum number of settlers observed per settlement season was assumed to indicate settlement success, for each transect and year. Recruitment level for each species was estimated using the number of individuals left after the end of the settlement season, when no new settlers (unpigmented or slightly pigmented fish) were observed.

Because of the different numbers of transects for each locality, data from transects within localities were pooled. As a result of the differences in lengths of these transects, numbers of settlers were standardized to ind. $\mathrm{m}^{-2}$ suitable substrate. Suitable habitat for Aidablennius sphynx was bare rock. For Parablennius incognitus and Tripterygion tripteronotus cover of small turf algae $(0.5$ to $1 \mathrm{~cm}$ in height) were used These algal covers were determined as the preferred substrate for each species (see 'Results'). The variation of settlement and recruitment between localities and years was then determined in a 2 -factor ANOVA. The differences among means were assessed using the Tukey HSD test.

We also tested if settlement and recruitment success were influenced by the sizes of the transects. The same standardised data set as above was used. A general linear regression model was applied to analyse the relationship between the abundance of settlers and recruits and the amount of suitable substrate available for each transect.

In addition to the statistics described above, we tested for outliers by plotting means versus standard deviations. Cochran's test was used to test for heterogeneity of variances. However, no transformations were effective; therefore, raw data were used since sample sizes were sufficiently large to minimize Type I error (Underwood 1997).

\section{RESULTS}

The weekly censuses showed that settlement season started in second half of June for Aidablennius sphynx, in the first half of July for Parablennius incognitus and Tripterygion tripteronotus, lasting until October for all 3 species. Settlement patterns were found to be similar for all 3 blennoids: few settlers per day and no shoal aggregations on the substrate.
Once settled, fish remain benthic and live in the same habitats as adult conspecifics. Settlers of A. sphynx and $T$. tripteronotus remained on the surface of the rock, their colour pattern matching the substratum. Settlers of $P$. incognitus also have their colour matching the environment, although they used the rugosity of the rocks as hiding places. Peak settlement was recorded during the second half of August and first half of September, between 8 and 11 wk after the arrival of the first settlers for A. sphynx, and 5 to $8 \mathrm{wk}$ for $P$. incognitus and $T$. tripteronotus. The last few settlers of $P$. incognitus and $T$. tripteronotus were observed in the last half of September, and of $A$. sphynx in the first half of October. No clear differences in the timing of first arrival of settlers was observed between localities and years.

\section{Effect of habitat characteristics on settlement}

The means of the 7 different substratum characteristics did not change significantly between each transect of each locality during the settlement season (KruskalWallis test, $\mathrm{p}>0.95$, in all cases) or between years (Kruskal-Wallis test, $p>0.80$, in all cases). This consistency was in a large part a result of the algae Corallina elongata, which maintains a near constant coverage over years and within seasons (Ballesteros 1987). For this reason, and in order to simplify further analysis for each locality, data from transects were pooled for each locality.

The results from the stepwise multiple regression analysis indicate that the type of algal cover and the presence of adult conspecifics significantly effect the abundance of settlers and post-settlers on the rocky shore of all 3 species (Table 1). However, the preferred substrate type and other wall characteristics differ between the species. The variation in the abundance of Aidablennius sphynx is best explained by the category 'bare rock'. The amount of variance explained by the multiple regression of this type of cover is high in all 3 localities with the highest correlations occurring in Blanes and Port de la Selva. Negative correlations were obtained for long turf algae, Mytilus galloprovincialis, rugosity and slope in some localities.

Settlement variance of Parablennius incognitus and Tripterygion tripteronotus was mainly explained by the substrate covered with 'small turf of algae'. In both species the amount of variance explained is higher in Port de la Selva than in the other localities. The importance of the other substrate characteristics differ between the species (e.g. rugosity is positively related with $P$. incognitus, slope negatively with T. tripteronotus). 
Table 1 Stepwise multiple regression coefficients for sources of variation of settlement of (A) Aidablennius sphynx, (B) $p_{a r a-}$ blennius incognitus, and (C) Tripterygion tripteronotus, for different localities. The dependent variables are the 7 characteristics of the habitat (type of algal cover, Mytilus galloprovincialis, rugosity, and slope) and 2 fish variables (number of adult conspecifics and non-conspecifics). Only significant relationships are shown $(\cdots p<0.001, \cdots p<0.01, \cdot p<0.05)$

\begin{tabular}{|c|c|c|c|c|c|c|c|c|c|}
\hline \multirow{2}{*}{ Independent variable } & \multicolumn{3}{|c|}{ Blanes } & \multicolumn{3}{|c|}{ Medes Islands } & \multicolumn{3}{|c|}{ Port de la Selva } \\
\hline & Coefficient & Partial $r^{2}$ & $\mathrm{p}$ & Coefficient & Partial $r^{2}$ & $\mathrm{p}$ & Coefficient & Partial $r^{2}$ & $\mathrm{p}$ \\
\hline \multicolumn{10}{|c|}{ (A) Aidablennius sphynx } \\
\hline No algae (to scarce) & 0.249 & 0.491 & $\cdots$ & 0.855 & 0.350 & $\cdots$ & 0.434 & 0.424 & $\cdots$ \\
\hline Long turf algae & -0.347 & 0.011 & $\cdot$ & & & & -0.715 & 0.105 & $\cdots$ \\
\hline Mytilus & & & & & & & -1.150 & 0.011 & $\cdot$ \\
\hline Rugosity & & & & & & & -0.256 & 0.029 & $\cdots$ \\
\hline Slope & & & & -0.659 & 0.047 & $\cdots$ & -0.276 & 0.007 & $\cdot$ \\
\hline Adult conspecifics & 0.483 & 0.051 & $\cdots$ & 0.208 & 0.027 & $\cdots$ & & & \\
\hline \multicolumn{10}{|c|}{ (B) Parablennius incognitus } \\
\hline Small turf algae & 0.226 & 0.136 & .. & 0.243 & 0.022 & $\cdot$ & 1.706 & 0.448 & $\cdots$ \\
\hline Rugosity & & & & & & & 0.607 & 0.022 & $\cdots$ \\
\hline Adult conspecifics & 0.095 & 0.087 & $\cdots$ & 0.591 & 0.323 & $\cdots$ & 0.348 & 0.037 & $\cdots$ \\
\hline \multicolumn{10}{|c|}{ (C) Tripterygion tripteronotus } \\
\hline Small turf algae & 0.376 & 0.332 & $\cdots$ & 0.090 & 0.251 & $\cdots$ & 0.676 & 0.343 & $\cdots$ \\
\hline Slope & & & & -0.179 & 0.046 & $\cdots$ & -0.149 & 0.119 & $\cdots$ \\
\hline Adult conspecifics & 0.168 & 0.171 & $\cdot$ & 0.243 & 0.069 & $\cdots$ & & & \\
\hline
\end{tabular}

\section{Test of the effect of algal density on settlement}

The results from the 2-factor ANOVA show that only the percentage of algal cover explains the variance of abundance of settlers. No significant differences exist over time. Furthermore, algal cover and sampling date interaction show no significant relationship (Table 2); consequently, data collected on different days were pooled for further analyses. Aidablennius sphynx settled in quadrants with high abundance of 'bare rock' $(80 \%)$. Settlement did not occur if this substrate type was less frequent than $50 \%$. Mean abundances were significantly higher (Tukey HSD test) in quadrants



Fig. 2. Effect of 3 densities of preferred substrate on the density of blennoid settlers (mean $\pm \mathrm{SE}$ ). 'Bare rock' cover type was tested for Aidablennius sphynx (AS), 'small turf algae' cover type for Parablennius incognitus (PI), and Tnpterygion tripteronotus (TT). Three different levels of preferred substrate densities (low, 20\%; medium, 50\%; and high, $>80 \%$ cover) were used with low algal densities, but high abundance of 'bare rock' (high $>$ medium $>$ low, $\mathrm{p}=0.0001$ ), and no differences between medium and low densities of 'bare rock' were found ( $\mathrm{p}=0.98$, Fig. 2). Parablennius incognitus preferred to settle on high algal densities (> $80 \%$ ) of 'small turf of algae'. Mean settlement abundances were significantly higher in quadrants with high algal densities than with medium (50\%) and low $(<20 \%)$ densities ( $p=0.04$, Fig. 2). Tripterygion tripteronotus showed an intermediate pattern, with no preference between medium and high densities of algal cover. When the densities of $50 \%$ turf algae and $50 \%$ bare rock could be selected, quadrants with low density cover $(<20 \%)$ were avoided ( $p=0.0002$, Fig. 2$)$

Based on results from experiments on algal densities and habitat characteristics, the hypothesis that algae cover on this coast effects settlement of larval fish is accepted. A strong effect of substrate type on settlement of Aidablennius sphynx, Parablennius incognitus and Tripterygion_tripteronotus seems to exist.

\section{Test of the effect of presence/absence of conspecifics} on settlement

A significant relationship between conspecific presence or absence could not be found for any of the 3 species. Neither temporal variation or an influence of the combination factors detected a significant relationship with the abundance of settlers (2-factor ANOVA, Table 3). Fig. 3 shows the mean number of settlers in 
Table 2. Results of a 2-factor analysis of variance used to determine if the number of newly settled individuals of the species (A) Aidablennius sphynx, (B) Parablennius incognitus, and (C) Tripterygion tripteronotus is influenced by the algal density in the experimental quadrants $\left(1 \mathrm{~m}^{2}\right)$. Three different densities of algal cover per quadrant were tested: low $(<20 \%)$, medium $(50 \%)$ and high $(>80 \%)$, with 4 replicates at each density. Selected algae cover varied between species: no algae (to scarce), small algae, $<0.5 \mathrm{~cm}$ for $A . s p h$ $y n x$; and small turf algae, 0.5 to $1.0 \mathrm{~cm}$ for $P$. incognitus and $T$ tripteronotus (see 'Results' for further explanation). Day refers to sampling days

\begin{tabular}{|lrrrr|}
\hline Source & df & MS & $F$ & $p$ \\
\hline (A) Aidablennius sphynx & & & & \\
Day (A) & 2 & 0.282 & 2.096 & 0.100 \\
Algal cover (B) & 2 & 7.801 & 58.044 & 0.000 \\
A $\times$ B & 4 & 0.249 & 1.855 & 0.091 \\
Error & 45 & 0.134 & & \\
& & & & \\
(B) Parablennius incognitus & & & & \\
Day (A) & 2 & 0.238 & 1.007 & 0.414 \\
Algal cover (B) & 2 & 5.533 & 23.440 & 0.000 \\
A $\times$ B & 4 & 0.112 & 0.476 & 0.867 \\
Error & 45 & 0.236 & & \\
(C) Tripterygion tripteronotus & & & & \\
Day (A) & 2 & 0.245 & 1.000 & 0.417 \\
Algal cover (B) & 2 & 1.718 & 7.018 & 0.002 \\
A $\times$ B & 4 & 0.102 & 0.418 & 0.904 \\
Error & 45 & 0.245 & & \\
\hline
\end{tabular}

quandrants with adult conspecifics present or absent. Mean settler abundances were not found to be significantly different between quadrants (HSD Tukey test, $p>0.7$ ). Thus, the hypothesis that settlement is directly affected by adult conspecifics, occupying the same habitat as settlers, is not accepted since no significant relationship was detected. The strong correlation between settlers and adult conspecifics in the stepwise multiple regression, therefore, seems to be causal.

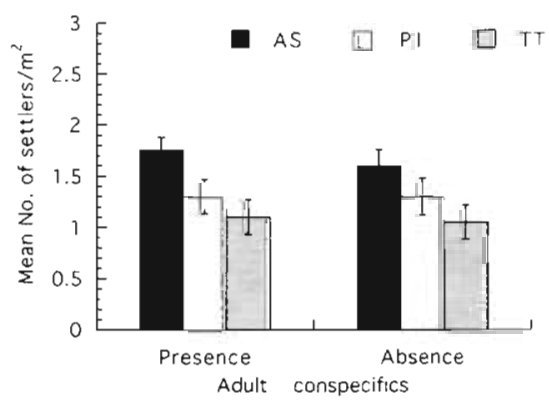

Fig. 3. Effect of the presence and absence of adult conspecifics on the settler densities (mean $\pm \mathrm{SE}$ ) of Aidablennius sphynx (AS), Parablennius incognitus (PI), and Tripterygion tripteronotus (TT)
Table 3. Results of a 2 -factor analysis of variance used to determine if the number of newly settled individuals of the species (A) Aidablennius sphynx, (B) Parablennius incognitus, and (C) Tripterygion tripteronotus is influenced by the presence or the absence of adult conspecifics in the experimental quadrants $\left(1 \mathrm{~m}^{2}\right)$. Between 1 and 3 adults were present per quadrant. Day represents sampling days

\begin{tabular}{|lrrcc|}
\hline Source & df & MS & $F$ & $\mathrm{p}$ \\
\hline (A) Aidablennius sphynx & & & & \\
Day (A) & 2 & 0.038 & 0.441 & 0.778 \\
Adults (B) & 1 & 0.226 & 2.588 & 0.118 \\
A $\times$ B & 2 & 0.029 & 0.333 & 0.853 \\
Error & 30 & 0.087 & & \\
& & & & \\
(B) Parablennius incognitus & & & & \\
Day (A) & 2 & 0.124 & 0.742 & 0.571 \\
Adults (B) & 1 & 0.012 & 0.072 & 0.790 \\
A $\times$ B & 2 & 0.060 & 0.361 & 0.834 \\
Error & 30 & 0.167 & & \\
(C) Tripterygion tripteronotus & & & & \\
Day (A) & 2 & 0.102 & 0.485 & 0.747 \\
Adults (B) & 1 & 0.004 & 0.195 & 0.890 \\
A $\times$ B & 2 & 0.034 & 0.162 & 0.956 \\
Error & 30 & 0.211 & & \\
\hline
\end{tabular}

\section{Variations in settlement success and recruitment level between localities and years}

Settlement success of the 3 species studied for different localities and years is shown in Fig. 4. For all analyses of variance Tukey HSD tests were carried out (see 'Material and methods'), but for simplicity only significant pairwise comparisons are noted. ANOVAs showed no spatial (between localities) or temporal (between years) differences in settlement success for Aidablennius sphynx or Parablennius incognitus (Table 4). For Tripterygion tripteronotus, however, settlement success varied significantly between years, with higher settlement success in 1997 than in other years (Tukey HSD test, $p<0.007$ ), and between localities, with higher settlement success in Medes (Tukey HSD test, $\mathrm{p}<0.02$ ). The number of recruits ( $A$. sphynx $r^{2}=0.64, P$. incognitus $r^{2}=0.66$ and $T$. tripteronotus $r^{2}=0.86, p<0.00001$ in all cases) was positively and significantly correlated with the maximum number of settlers for each species. However, the 2-way ANOVA performed on recruitment level data showed a different result than the results from settlement success (Table 4, Fig. 5). Recruitment for A. sphynx was significantly higher in Port de la Selva than in Blanes (Tukey HSD test, $p=0.05$, recruitment level of 1997 was significantly higher than in previous years (Tukey HSD test, $\mathrm{p}=0.02$ ). For $P$. incognitus spatial and temporal patterns of recruitment level were quite similar as for settlement success, the exception was Port de la Selva 
Table 4. Results of a 2-factor analysis of variance used to determine differences in settlement success and recruitment level of the species (A) Aidablennius sphynx. (B) Parablennius incognitus, and (C) Tripterygion tripteronotus, between the 4 sampling years (1994 to 1997) and the 3 localities (Blanes, Medes Islands, and Port de la Selva)

\begin{tabular}{|lrrrr|}
\hline \multicolumn{1}{c}{ Settlement } & & & & \\
Source & df & MS & $F$ & $\mathrm{p}$ \\
\hline (A) Aidablennius sphynx & & & & \\
Year (A) & 3 & 23.727 & 2.600 & 0.064 \\
Locality (B) & 2 & 27.410 & 3.004 & 0.060 \\
A $\times$ B & 6 & 3.842 & 0.421 & 0.861 \\
Error & 44 & 9.123 & & \\
& & & & \\
(B) Parablennius incognitus & & & & \\
Year (A) & 3 & 0.038 & 0.441 & 0.778 \\
Locality (B) & 2 & 0.226 & 2.588 & 0.118 \\
A $\times$ B & 6 & 0.029 & 0.333 & 0.853 \\
Error & 44 & 0.575 & & \\
(C) Tripterygion tripteronotus & & & & \\
Year (A) & 3 & 3.740 & 13.564 & 0.000 \\
Locality (B) & 2 & 1.399 & 5.074 & 0.010 \\
A $\times$ B & 6 & 0.286 & 1.038 & 0.414 \\
Error & 44 & 0.276 & & \\
\hline
\end{tabular}

with significantly higher levels than Blanes (Tukey HSD test, $\mathrm{p}=0.001$ ). For $T$. tripteronotus, recruitment level did not vary significantly between localities, but was clearly different between years, with higher levels in 1997 than in previous years (Tukey HSD test, $\mathrm{p}=0.0003$ )

To test the relationship of the amount of suitable substrate on settlement success, a general linear regression between the maximum abundance of settlers per transect and the amount of suitable substrate available per transect was carried out. Data from all localities and years were pooled. A significant relationship was found for Aidablennius sphynx $\left(\mathrm{r}^{2}=0.79\right.$, $\mathrm{p}<0.001)$ and Parablennius incognitus, $\left(\mathrm{r}^{2}=0.78\right.$, $\mathrm{p}<0.001$ ) (Fig. 6A,B). No relationship was found $\left(\mathrm{r}^{2}=0.19, \mathrm{p}=0.001\right)$ for Tripterygion tripteronotus. As noted from the statistical results above, for $T$. tripteronotus, highest densities were found in Medes and in 1997. When a linear regression was repeated using only the data sets for Medes $\left(r^{2}=0.32\right.$, $\mathrm{p}<0.01)$ and for all localities in $1997\left(\mathrm{r}^{2}=0.72\right.$, $\mathrm{p}<0.001$ ), a better relationship was found (Fig. 6C). The combination of the 2 gave the highest correlation between maximum numbers of settlers and amount of available suitable habitat $\left(\mathrm{r}^{2}=0.95, \mathrm{p}<0.005\right)$. To test if settlement was lower on isolated patches of suitable habitat versus continuous, larger areas of suitable habitat, different models were applied on settlers, standardized by the area of suitable habitat (no. per $\mathrm{m}^{2}$ suitable habitat), and the amount of suitable habitat available per transect. No relationship was found for all 3 species. Thus, the abundance of settlers per

\begin{tabular}{|lrrrc|}
\hline \multicolumn{1}{c}{ Recruitment } & & & & \\
Source & df & MS & $F$ & $p$ \\
\hline (A) Aidablennius sphynx & & & & \\
Year (A) & 3 & 17.778 & 3.276 & 0.029 \\
Locality (B) & 2 & 19.682 & 3.627 & 0.034 \\
A $\times$ B & 6 & 5.782 & 1.066 & 0.397 \\
Error & 44 & 5.426 & & \\
& & & & \\
(B) Parablennius incognitus & & & & \\
Year (A) & 3 & 0.672 & 2.183 & 0.103 \\
Locality (B) & 2 & 2.309 & 7.500 & 0.002 \\
A $\times$ B & 6 & 0.416 & 1.350 & 0.256 \\
Error & 44 & 0.308 & & \\
& & & & \\
(C) Tripterygion tripteronotus & & & & \\
Year (A) & 3 & 1.494 & 19.123 & 0.000 \\
Locality (B) & 2 & 0.178 & 2.282 & 0.113 \\
A $\times$ B & 6 & 0.043 & 0.556 & 0.762 \\
Error & 44 & 0.078 & & \\
\hline
\end{tabular}

surface area of suitable substrate is independent of the amount of the preferred substrate available along a transect (Fig 7 ).

\section{DISCUSSION}

Substratum characteristics clearly influence the small-scale settlement of the 3 blennoid fishes. New individuals of Aidablennius sphynx occupied quadrants with a higher percent of rocky areas with no algal to scarce algal cover or covered by encrusting or occasional small algae. The other 2 species, Parablennius incognitus and Tripterygion tripteronotus, settled on clearly different substrata dominated by small turf algae. On the other hand, the presence or absence of adult conspecifics seems not to have a significant effect on settlement of the 3 species. Similar relationships have been described for other tropical and temperate fishes in which habitat characteristics influenced settlement (Sale et al. 1984, Doherty 1991, Levin 1991, Williams 1991). Some authors have analysed the relationship between the density of new settlers and some substratum variables, finding different patterns. Marliave (1977) found that newly settling littoral fishes (e.g. Artedius lateralis, Leptocottus armatus) show substratum preferences based on tactile cues and light transmission. Carr $(1991,1994)$ demonstrated that spatial and temporal variation in the density of the giant kelp Macrocystis pyrifera explained much of the variation in the recruitment of Paralabrax clathratus as well as in other rockfish species. Macpherson (1998) found 
that settlers belonging to 3 species of the genus Diplodus showed a clear preference for specific habitats. A range of effects of adult conspecifics have been demonstrated, either a facilitation (Forrester 1990), inhibition (Shulman 1985, Tupper \& Hunte 1994) or no effect on settlement (Doherty 1983, Sweatman 1985, Tupper \& Boutilier 1995). Levin (1993) demonstrated that resident conspecifics of Tautogolabrus adspersus did not affect small-scale variability in recruitment, where recruitment was higher in areas with dense understory of foliose and filamentous algae than in substrates covered by crustose algae. For this species, algal cover was an important predictor of variability in recruit abundance in one region, but not in others (Levin et al. 1997). Booth (1992) found that juveniles of Dascyllus albisella do not interact with adults, being conspecific juvenile density a major factor influencing settlement. The presence of conspecifics reduced set-
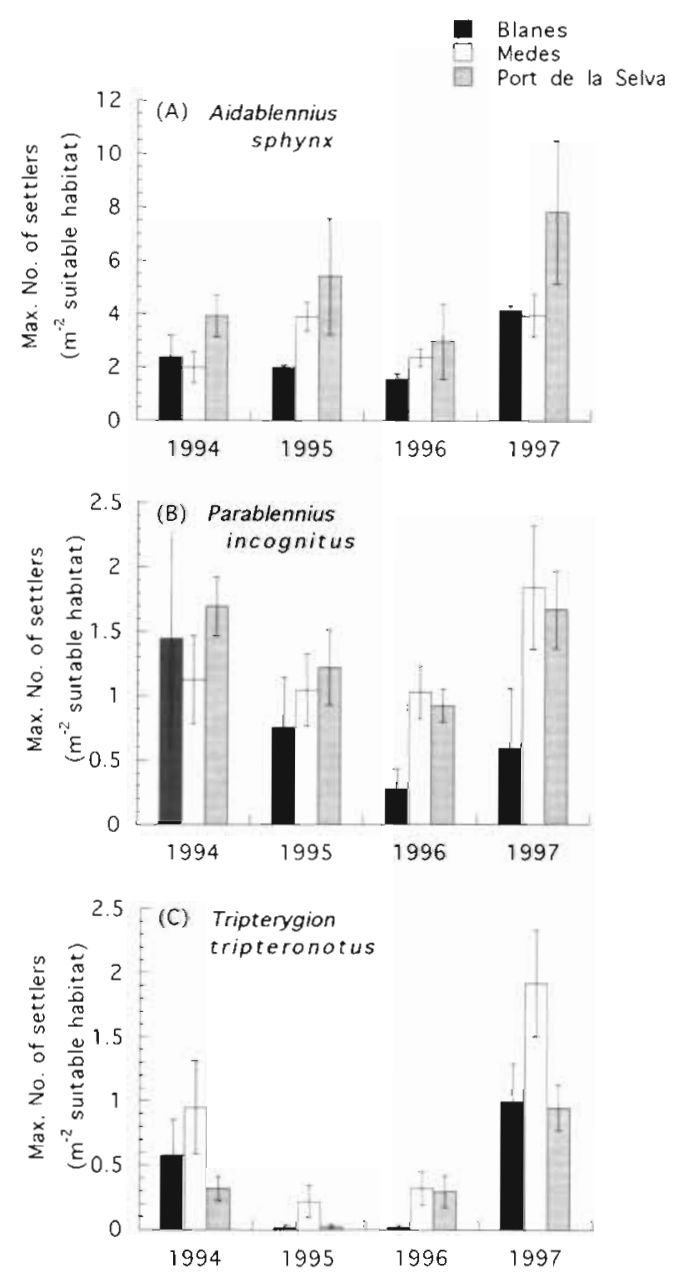

Fig. 4. Maximum density (mean per transect and $\mathrm{m}^{2} \pm \mathrm{SE}$ ) of settlers for (A) Aidablennius sphynx, (B) Parablennius incognitus, and (C) Tnipterygion tripteronotus observed per locality and per year. The maximum density is taken as an estimate of settlement success. Note that $y$-axes vary for the 3 species



Fig. 5. Density (mean per transect and $\mathrm{m}^{2} \pm \mathrm{SE}$ ) of recruits for (A) Aidablennius sphynx, (B) Parablennius incognitus, and (C) Tripterygion tripteronotus observed at the end of the settlement season per locality and per year. Note that $y$-axes vary for the 3 species

tlement in Stegastes planifrons, but the percent cover of corals can affect significantly settlement dynamics (Tolimieri 1995).

Microhabitat choice at settlement of the 3 species matched quite well the pattern of adult conspecific distribution. Therefore, the substrate selection could confer a greater fitness on preferred microhabitat, as has been observed in Stegastes planifrons, S. leucostictus and S. variabilis from the Caribbean Sea (Wellington 1992, Tolimieri 1995). Settlers of the 3 blennoid species showed similar behaviour as adults (Zander 1986, Abel 1993), remaining in the same type of habitats. Similar behaviour patterns were observed by other authors in littoral species (Marliave 1977). The overlap between adult and settler distributions for the 3 species suggests that the selected habitat at settlement can provide some advantages for the species, for example, protection and food. 

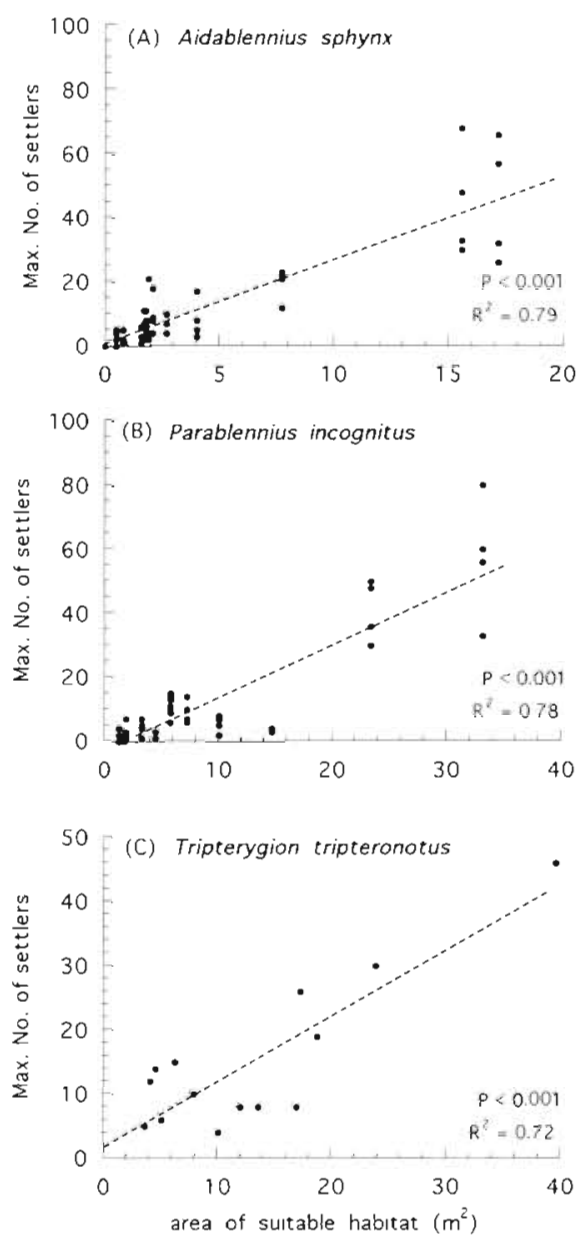

Fig. 6. Relationship between settlement success and suitable habitat available per transect for (A) Aidablennius sphynx, (B) Parablennius incognitus, and (C) Tripterygion tripteronotus. For $A$. sphynx and $P$. incognitus all years and transects are shown, while for $T$ tripteronotus only 1997 is shown for all transects (see 'Results' for further explanations). Note that $x$-and $y$-axes vary for the 3 species

Several authors (Levin 1993, Tolimieri 1995) suggested that for species where adults and juveniles shared the same habitats, their co-occurrence indicated suitable zones for an adequate development. Consequently, differences in the adult abundances can be attributed to differential settlement (Fowler et al. 1992, Risk 1997). In the present study, the relationship between settlers, recruits, and adult distributions has not been evaluated as it has in other studies (e.g. Wellington 1992) and further studies with more detail need to be done. Gibson (1993) emphasised that future studies should be conducted on settlement distribution patterns, analysing if the patterns are the result of an initial choice by larvae or if preferred substratum is chosen after random settlement, or if it simply results from an elimination of individuals from unfavourable habitats (also see Connell \& Jones 1991).
For the 3 blennoids studied here, preferences for a specific substratum type at settlement can explain, on the small scale, the abundance of new settlers in a locality. This abundance will be related to the availability of habitat suitable for the species and, additionally, will be independent of the rocky reef size. Similar results have been provided by other authors in coral reef fishes (Williams 1991, Fowler et al. 1992, Tolimieri 1995, Risk 1997). Although the variations in habitat can explain much of the variation in settlement success and recruitment (Carr 1994), some important considerations should be taken into account in order to understand the variability on different spatial and temporal scales. The amount of suitable habitat accounts for some of the variation of settlement success; thus, the large varia-
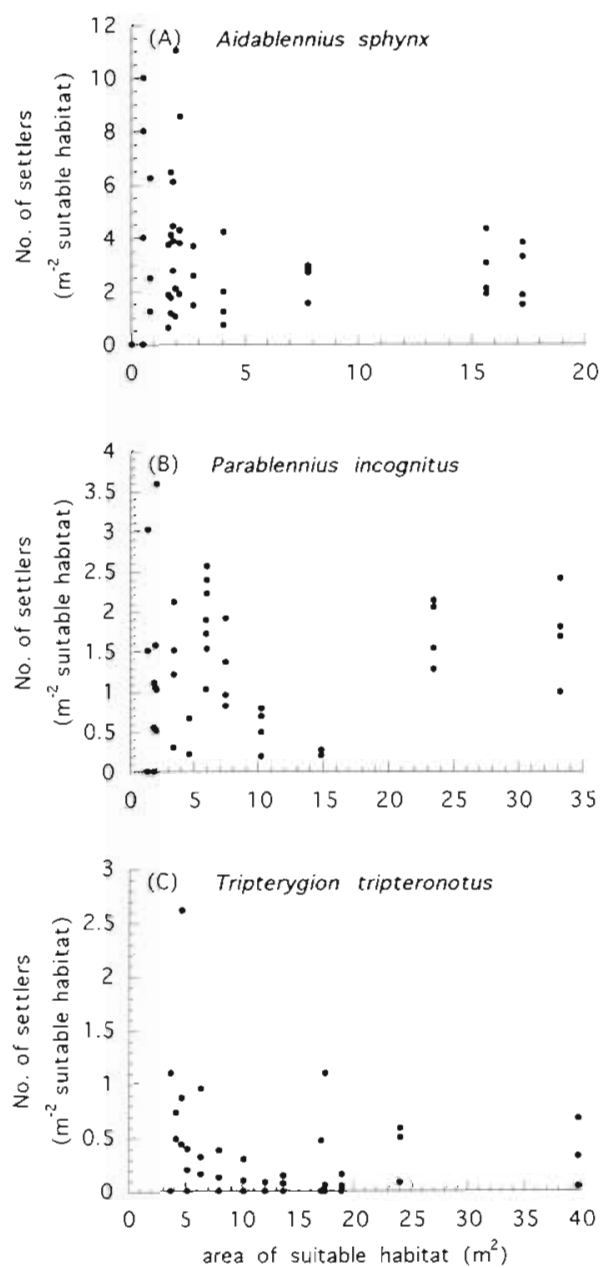

Fig. 7. Relationship between settlers standardized by the area of suitable habitat and the amount of suitable habitat available per transect for (A) Aidablennius sphynx, (B) Parablennius incognitus, and (C) Tripterygion tripteronotus. For A. sphynx and $P$. incognitus all years and transects are shown, while for $T$. tripteronotus only 1997 is shown for all transects (see text for further explanations). Note that $x$ - and $y$-axes vary for the 3 species 
bility observed in maximum settler density for the 3 blennoids suggests that, additionally, other processes are influencing settlement and later recruitment.

Numerous authors have emphasised the importance of analysing the relationship between settlement, recruitment, and habitat availability at different scales, in order to know how well patterns exhibited at small scales explain patterns observed at larger scales (Doherty 1991, Caley et al. 1996). This analysis is a central topic in ecological studies to determine the mechanisms influencing population dynamics of any species (Dayton \& Tegner 1984, Levin 1988). Unfortunately, comparisons of different spatial and temporal scales are rarely done in studies of fishes and invertebrates. Fowler et al. (1992), working on recruits of Chaetodon rainfordi at different spatial scales (from regions separated by hundreds of $\mathrm{km}$ at different sites on a coral reef), found that the distribution pattern of recruitment was consistent each year, and several regions always had higher recruitment rates than others. Tolimieri (1995) showed that microhabitat choice had consequences on the small-scale recruitment patterns of Stegastes planifrons, but not on the large-scale variation. Levin et al. (1997) found that the variation in the densities of newly recruited individuals of Tautogolabrus adspersus was pronounced among sites (separated by 100 to $1000 \mathrm{~m}$ ) and among localities (separated by ca $10 \mathrm{~km}$ ), but this pattern was not geographically homogeneous but distinct to geographic regions. Vigliola et al. (1998) observed that for 3 species of Diplodus on a large scale (ca $1000 \mathrm{~km}$ of coast line) the spatial variability of settlement was higher than the temporal variability, whereas on small scale, within localities, the temporal variability was higher. Settlement success patterns of Aidablennius sphynx and Parablennius incognitus did not differ between the 3 localities situated along $150 \mathrm{~km}$ coast line and separated ca $50 \mathrm{~km}$ from each other. Furthermore, the settlement success did not show any significant differences among years. These results would suggest that processes affecting settlement success at small scale did not differ from patterns observed at larger scales. Tripterygion tripteronotus, however, showed temporal and spatial differences.

These different patterns could be driven by processes occurring at different stages in the life of fishes, during pre-settlement or at any time during and after settlement. The importance of pre-settlement versus post-settlement processes in determining year-class strength has been widely disputed. Larval supply to a locality is thought to be a major cause of variability in settlement success of fishes (Victor 1991) and it has been considered a primary factor in the population dynamics of many fish communities (Sale 1982, Doherty 1991, Cushing 1996). Larvae of Aidablennius sphynx and Parablennius incognitus have a distribution pattern clearly different than the one observed in Tripterygion tripteronotus. Larvae of the former species are distributed offshore, on the continental shelf and slope (Sabates 1994), whereas larvae of T. tripteronotus are as in most Tripterygiidae (Brogan 1994, Leis 1994), located inshore, between the coastline and 100 to $200 \mathrm{~m}$ offshore (Sabates pers. comm.). These differences in larval distributions, could explain, at least partially, differences observed in the pattern of settlement success. Species situated on the continental shelf are influenced by mesoscale processes, as observed in other Mediterranean species, i.e. Diplodus sargus (Vigliola et al. 1998), which would result in a more homogeneous spatial pattern of settlement. On the other hand, settlement of $T$. tripteronotus, could be more dependent on microscale processes, quite common in the tortuous coast of the NW Mediterranean (Ros et al. 1985), and on local oceanographic events, e.g. currents, storms, waves (Kingsford \& Choat 1989, Breitburg et al. 1995, Jenkins et al. 1997). The relationship between larval and settler distributions has been analysed by several authors (see the abovementioned references) for different areas; however, the above stated hypotheses need to be investigated further and the relevant physical oceanographic processes influencing settlement on this coast determined.

The differences observed between spatial and temporal variability in settlement success and recruitment levels for each blennoid species calls the attention to the interpretation of the results. Differences between settlement and recruitment patterns can provide a more complete view of the importance of post-settlement processes and the necessity for further research. The highest significant differences (yearly variability in Tripterygion tripteronotus) were reflected in both settlement and recruitment patterns, which suggests that the interannual differences are very strong and are maintained throughout the post-settlement period. The minor differences of settlement success between localities for this species, however, were not maintained over the season. On the other hand, for Aidablennius sphynx, temporal and spatial differences were not found significant for settlement success but were significant for recruitment level. For Parablennius incognitus no significant differences were found for settlement success, but a significant spatial variation in recruitment level was observed. Although correlations between settlement success and recruitment are highly significant (by the order of magnitude), the results from the ANOVA (based on variance between means) demonstrate that post-settlement processes can alter patterns of settlement success and therefore, are able to change spatial and/or temporal recruitment patterns. The period following settlement 
can be dominated by high mortality, probably as a result of predation or competition (e.g. Pfister 1995 , 1996, Booth 1995, Beets 1997, Hixon \& Carr 1997, Macpherson et al. 1997, Connell 1998), which could easily alter settlement patterns and subsequent recruitment level. Recruitment patterns are believed to influence the dynamics of the adult population (Cushing 1996). The differences between patterns of settlement success and recruitment level presented in the present study stress the complexity of processes occurring between the arrival of settlers and their recruitment.

Acknowledgements. Thanks are expressed to X. Turon, A. Gordoa, M. J. Uriz, A. García-Rubies, T. Granata, E. Sala, and anonymous reviewers for helpful comments and suggestions that improved the manuscript. Thanks are also expressed to E. Benavent and G. Agell for their assistance in collecting data. This research was funded by project DGCYT PB94-0015 of the Spanish Government.

\section{LITERATURE CITED}

Abel EF (1993) Coloration phenomena of Mediterranean Blennies (Pisces, Blenniidae). PSZN I: Mar Ecol 14:291-312

Almada VC, Santos RS (1995) Parental care in the rocky intertidal: a case of study of adaptation and exaption in Mediterranean and Atlantic blennies. Rev Fish Biol. Fish 5:23-37

Bailey KM (1994) Predation on juvenile flatfish and recruitment variability. Neth J Sea Res 32:175-189

Bailey KM, Canino MF, Napp JM, Spring SM, Brown AL (1995) Contrasting years of prey levels, feeding conditions and mortality of larval walleye pollock Theragra chalcogramma in the western Gulf of Alaska. Mar Ecol Prog Ser 119:11-23

Ballesteros E (1987) Composición y estructura de la comunidad infralitoral de Corallina elongata Ellis \& Solander, 1786, de la Costa Brava (Mediterráneo occidental). Invest Pesq 52:135-151

Beets J (1997) Effects of a predatory fish on the recruitment and abundance of Caribbean coral reef fishes. Mar Ecol Prog Ser 148:11-21

Booth DJ (1992) Larval settlement patterns and preferences by domino damselfish Dascyllus albisella. J Exp Mar Biol Ecol 155:85-104

Booth DJ (1995) Juvenile groups in a coral-reef damselfish density-dependent effects on individual fitness and population demography. Ecology 76:91-106

Booth DJ, Beretta GA (1994) Seasonal recruitment, habitat associations and survival of pomacentrid reef fish in the US Virgin Islands. Coral Reefs 13:81-89

Breitburg DL, Palmer MA, Loher T (1995) Larval distributions and the spatial patterns of settlement of an oyster reef fish: responses to flow and structure. Mar Ecol Prog Ser 125:45-60

Brogan MW (1994) Distribution and retention of larval fishes near reefs in the Gulf of California. Mar Ecol Prog Ser 115: $1-13$

Caley MJ, Carr MH, Hixon MA, Hughes TP, Jones GP, Menge BA (1996) Recruitment and the local dynamics of open marine populations. Annu Rev Ecol Syst 27:477-500

Carr MH (1991) Habitat selection and recruitment of an assemblage of temperate zone reef fishes. J Exp Mar Biol Ecol 146:113-137
Carr MH (1994) Effects of macroalgal dynamics on recruitment of a temperate reef fish. Ecology 75:1320-1333

Caselle JE, Warner RR (1996) Variability in recruitment of coral reef fishes: the importance of habitat at two spatial scales. Ecology 77:2488-2504

Connell SD (1997) The relationship between large predatory fish and recruitment and mortality of juvenile coral reeffish on artificial reefs. J Exp Mar Biol Ecol 209:261-278

Connell SD (1998) Effects of predators on growth, mortality and abundance of a juvenile reef-fish: evidence from manipulations of predator and prey abundance. Mar Ecol Prog Ser 169:251-261

Connell SD, Jones GP (1991) The influence of habitat complexity on postrecruitment processes in a temperate reef fish population. J Exp Mar Biol Ecol 151:271-294

Corbera J, Sabates A, Garcia-Rubies A (1996) Peces de mar de la Peninsula Iberica. Ed Planeta, Barcelona

Cowen RK (1985) Large scale pattern of recruitment by the labrid, Semicossyphus pulcher: causes and implications. J Mar Res 43:719-742

Cushing DH (1996) Towards a science of recruitment in fish population. Excellence in ecology, Book 7 Ecology Institute, Oldendorf/Luhe

Dayton PK, Tegner MJ (1984) The importance of scale in community ecology: a kelp forest with terrestrial analogs. In: Price PW, Slobodchikoff CN, Gaud WS (eds) A new ecology: novel approaches to interactive systems. Wiley \& Sons, New York, p 457-481

Doherty PJ (1983) Tropical ternitorial damselfishes: is density limited by aggression or recruitment? Ecology 64:176-190

Doherty PJ (1991) Spatial and temperature patterns in recruitment. In: Sale PF (ed) The ecology of fishes on coral reefs Academic Press, London, p 261-292

Doherty P, Fowler T (1994) An empirical test of recruitment limitation in a coral reef fish. Science 263:935-939

Forrester GE (1990) Factors influencing the juvenile demography of a coral reef fish population. Ecology 71:1666-1681

Fowler AJ, Doherty PJ, Williams DMcB (1992) Multi-scale analysis of recruitment of a coral reef fish on the Great Barrier Reef. Mar Ecol Prog Ser 82:131-141

García-Rubies A, Macpherson E (1995) Substrate use and temporal pattern of recruitment in juvenile fishes of the Mediterranean littoral. Mar Biol 124:35-42

Gibson RN (1993) Intertidal teleosts: life in a fluctuating environment. In: Pitcher TJ (ed) Behaviour of teleost fishes. Chapman \& Hall, London, p 513-536

Gordina AD, Duka LA, Oven LS (1972) Sexual dimorphism, feeding and spawning in the 'black-headed blenny' (Tripterygion tripteronotus Risso) of the Black Sea. J Ichthyol (USSR) 12:401-407

Harmelin-Vivien ML, Hármelin JG, Leboulleux F (1995) Microhabitat requirements for settlement of juvenile sparid fishes on Mediterranean rocky shores. Hydrobiologia 300/301:309-320

Hixon MA, Carr MH (1997) Synergistic predation, density dependence, and population regulation in marine fish. Science 277:946-949

Illich IP, Kotrschal K (1990) Depth distribution and abundance of northern Adriatic. Litoral rocky reef blennioid fishes (Blenniidae and Tripterygion). PSZN I: Mar Ecol 11:277-289

Jenkins GP, Black KP, Wheatley M.J, Hatton DN (1997) Temporal and spatial variability in recruitment of a temperate, seagrass-associated fish is largely determinated by physical processes in the pre-and post-settlement phases. Mar Ecol Prog Ser 148:23-35

Jones GP (1987) Competitive interactions among adults and juveniles in a coral reef fish. Ecology 68:1534-1547 
Jones GP (1991) Postrecruitment processes in the ecology of coral reef fish populations: A multifactorial perspective In: Sale PF (ed) The ecology of fishes on coral reefs. Academic Press, London, p 294-327

Kingsford MJ, Choat JH (1989) Horizontal distribution patterns of presettlement reef fish: are they influenced by the proximity of reefs? Mar Biol 101:285-297

Kingsford MJ, Wolanski E, Choat JH (1991) Influence of tidally-induced fronts and langmuir circulations on the distribution and movements of presettlement fishes around a coral reef. Mar Biol 109:167-180

Koppel VH (1988) Habitat selection and space partitioning among two Mediterranean Blenniid species. PSZN I: Mar Ecol 9:329-346

Kotrschal K, Goldschmid A (1981) Population structure of Blennius incognitus Bath 1968 (Pisces: Teleostei: Blenniidae) during the reproductive period with coments on age and growth of small benthic littoral fishes. PSZN I: Mar Ecol 2:225-240

Kraak SBM (1996) A quantitative description of the reproductive biology of the Mediterranean blenny Aidablennius sphynx (Teleostei, Blenniidae) in its natural habitat. Environ Biol Fishes 46:329-342

Leis JM (1994) Coral Sea atoll lagoons: closed nurseries for the larvae of a few coral reef fishes. Bull Mar Sci 54:206-227

Levin PS (1991) Effects of microhabitat on recruitment variation in a Gulf of Maine reef fish. Mar Ecol Prog Ser 75: $183-189$

Levin PS (1993) Habitat structure, conspecific presence and spatial variation in the recruitment of a temperate reef fish Oecologia 94:176-185

Levin PS (1994) Fine-scale temporal variation in recruitment of a temperate demersal fish: the importance of settlement versus post-settlement loss. Oecologia 97:124-133

Levin SA (1988) The problem of pattern and scale in ecology. Ecology 73:1943-1967

Levin PS, Chiasson W, Green JM (1997) Geographic differences in recruitment and population structure of a temperate reef fish. Mar Ecol Prog Ser 161:23-35

López S, Turon X, Montero E, Palacin C, Duarte CM, Tarjuelo I (1998) Larval abundance, recruitment and early mortality in Paracentrotus Lividus (Echinoidea). Interanual variability and plankton-benthos coupling. Mar Ecol Prog Ser 172:239-251

Luckhurst BE, Luckhurst K (1978) Analysis of the influence of the substrate variables on coral reef fish communities. Mar Biol 49:317-323

Mackenzie BR, Leggett WC (1991) Quantifying the contribution of small-scale turbulence to the encounter rates between larval fish and their zooplankton prey: effects of wind and tide. Mar Ecol Prog Ser 73:149-160

Macpherson E (1994) Substrate utilisation in a Mediterranean littoral fish community. Mar Ecol Prog Ser 114:211-218

Macpherson E (1998) Ontogenetic shifts in habitat use and aggregation in juvenile sparid fishes. $J$ Exp Mar Biol Ecol 220:127-150

Macpherson E, Biagi F, Francour P, Garcia-Rubies A, Harmelin $J$, Harmelin-Vivien M, Jouvenel JY, Planes S, Vigliola L, Tunesi L (1997) Mortality of juvenile fishes of the genus Diplodus in protected and unprotected areas in the western Mediterranean Sea. Mar Ecol Prog Ser 160:135-147

Marliave JB (1977) Substratum preferences of settling larvae of marine fishes reared in the laboratory. J Exp Mar Biol Ecol 27:47-60

Milicich MJ, Meekan MG, Doherty PJ (1992) Larval supply: a good predictor of recruitment of three species of reef fish (Pomacentridae). Mar Ecol Prog Ser 86:153-166
Pfister CA (1995) Estimating competition coefficients from census data: a test with field manipulations of tidepool fishes. Am Nat 146:271-291

Pfister CA (1996) The role and importance of recruitment variability to a guild of tide pool fishes. Ecology 77:1928-1941

Raimondi PT (1990) Patterns, mechanisms, consequences of variability in settlement and recruitment of an intertidal barnacle. Ecol Monogr 60:283-309

Risk A (1997) Effects of habitat on the settlement and postsettlement success of the ocean surgeonfish Acanthurus bahianus. Mar Ecol Prog Ser 161:51-59

Ros JD, Romero J, Ballesteros E, Gili JM (1985). Diving in blue water. The benthos. In: Margalef R (ed) Western Mediterranean. Pergamon Press, Oxford, p 233-295

Sabates A (1994) Larval development of three blenniid species Aidablennius sphynx, Coryphoblennius galerita and Lipophrys canevai (Pisces: Blenniidae: Blenniini) in the western Mediterranean. J Zool (Lond) 234:89-103

Sabates A, Maso M (1992) Unusual larval fish distribution pattern in a coastal zone of the western Mediterranean. Limnol Oceanogr 37:1252-1260

Sabates A, Olivar MP (1996) Variation of larval fish distributions associated with variability in the location of a shelfslope front. Mar Ecol Prog Ser 135:11-20

Sale PF (1982) Stock-recruit relationships and regional coexistence in a lottery competitive system: a simulation study. Am Nat 120:139-159

Sale PF, Doherty PJ, Eckert GJ, Douglas WA, Ferrell DJ (1984) Large scale spatial and temporal variation in recruitment to fish populations on coral reefs. Oecologia 64:191-198

Shulman MJ (1985) Variability in recruitment of coral reef fishes. J Exp Mar Biol Ecol 89:205-219

Shulman MJ, Ogden JC, Ebersole JP, MCFarland WN, Miller SL, Wolf NG (1983) Priority effects in the recruitment of juvenile coral reef fishes. Ecology 64:1508-1513

Sweatman HPA (1985) The influence of adults of some coral reef fishes on larval recruitment. Ecol Monogr 55:469-485

Sweatman HPA, St John J (1990) Effects of selective settlement and of aggression by residents on distribution of young recruits of two tropical damselfishes. Mar Biol 105:247-252

Tolimieri N (1995) Effects of microhabitat characteristics on the settlement and recruitment of a coral reef fish at two spatial scales. Oecologia 102:52-63

Tolimieri $N$ (1998) Contrasting effects of microhabitat use on large-scale adult abundance in two families of Caribbean reef fishes. Mar Ecol Prog Ser 167:227-239

Tupper M. Boutilier RG (1995) Effects of habitat on settlement, growth, and postsettlement survival of Atlantic cod (Gadus morhua). Can J Fish Aquat Sci 52:1834-1841

Tupper M, Hunte W (1994) Recruitment dynamics of coral reef fishes in Barbados, Mar Ecol Prog Ser 108:225-235

Underwood AJ (1997) Experiments in ecology: their logical design and interpretation using analysis of variance. Cambridge University Press, Cambridge

Uriz MJ, Maldonado M, Turon X, Marti R (1998) How do reproductive output, larval behaviour, and recruitment contribute to adult spatial patterns in Mediterranean encrusting sponges? Mar Ecol Prog Ser 167:137-148

Victor BC (1991) Settlement strategies and biogeography of reef fishes. In: Sale PF (ed) The ecology of fishes on coral reefs. Academic Press, London, p 231-260

Vigliola L, Harmelin-Vivien ML, Biagi F, Galzin R, GarciaRubies A, Harmelin JG, Jouvenel JY, LeDireach-Boursier L, Macpherson E, Tunesi I (1998) Spatial and temporal patterns of settlement among sparid fishes of the genus Diplodus in the north-western Mediterranean. Mar Ecol Prog Ser 168:45-56 
Wellington GM (1992) Habitat selection and juvenile persistence control the distribution of two closely related Caribbean damselfishes. Oecologia 90:500-508

Williams DMcB (1991) Patterns and processes in the distribution of coral reef fishes. In: Sale PF (ed) The ecology of fish on coral reefs. Academic Press, London, p 437-474

Editorial responsibility: Otto Kinne (Editor), Oldendorf/Luhe, Germany
Wirtz BP (1978) The behaviour of the Mediterranean Tripterygion species (Pisces, Blennioidei). Z Tierpsychol 48:142-174 Zander CD (1986) Blenniidae. In: Whitehead PJP, Bauchot $\mathrm{ML}$, Hureau JC, Tortonese E (eds). Fishes of the Northeastern Atlantic and the Mediterranean. UNESCO, Paris, p 1096-11.1.2

Submitted: September 21, 1998; Accepted: February 4, 1999 Proofs received from author(s): May 17, 1999 